\title{
ТЕХНОЛОГИИ 3D-ПЕЧАТИ КАК БАЗОВЫЕ ИННОВАЦИИ ДЛЯ УСКОРЕНИЯ НАУЧНО-ТЕХНОЛОГИЧЕСКОГО РАЗВИТИЯ РОССИИ
}

\author{
(C) 2019 Косакян Наринэ Левановна \\ магистр экономики \\ Финансовый университет при Правительстве Российской Федерации, Россия, Москва \\ E-mail: kosakyan-narine@mail.ru
}

B статье рассматриваются технологии 3D-печати в качестве фактора ускорения научно-технологического развития России. Описано применение технологий 3D-печати. Проработаны и представлены направления ускорения научно-технологического развития под влиянием технологий 3D-печати. Разработаны рекомендации по ускорению научно-технологического развития России на основе технологий 3D-печати.

Ключевые слова: 3D-печать, 3D-принтеры, технологии аддитивного производства, металлические порошки, фотополимерная смола

В условиях перманентных кризисных явлений в российской экономике, множество отраслей промышленности которой находятся в глубоком кризисе, стагнации или демонстрируют, за редким исключением, неуверенный рост и замедленное развитие, крайне важно разработать подходы к преобразованию отраслей промышленности России на основе самых современных технологий, которая позволит преобразовать всю экономику и резко ускорить социально-экономическое развитие России. На сегодняшний день самыми современными технологиями, готовыми к внедрению в производство, являются технологии аддитивного производства, основанные на послойной 3D-печати с использованием самых различных материалов, включая металлические порошки, специальный пластик для печати на 3D-принтерах, пластиковые порошки, фотополимерную смолу, керамические порошки, специальные пищевые ингредиенты, пригодные для 3D-печати на различных пищевых 3D-принтерах, деревянные пластики на основе древесной пыли (около 30\%) и полимерной основы (около 70\%) и т.д., на основе специально разработанных виртуальных 3D-моделей. Самое важное, что 3D-принтеры, являющиеся основным оборудованием для аддитивного производства, производятся не только за границей, но и в России. В Россию также поставляются 3D-принтеры иностранного производства. Предметом исследования данной статьи является воздействие персональных, профессиональных и промышленных 3D-принтеров на трансформацию отраслей промышленности России.
Следует отметить, что отечественными и зарубежными авторами опубликовано множество статей, в которых описываются изменения, вызываемые технологиями аддитивного производства, а также сами технологии аддитивного производства, в частности, в отраслях промышленности, занимающихся производством комплектующих и готовой продукции непосредственно из первичных сырьевых материалов, применяемых в 3D-печати, включая металлургическую промышленность [14, 12], керамическую промышленность [20], пластмассовую промышленность [8], пищевую промышленность [11] и т.д. Также следует отметить, что технологии аддитивного производства оказывают воздействие на сектора экономики и отрасли промышленности, использующие комплектующие и готовую продукцию, производимые на 3D-принтерах, включая медицину и стоматологию [13, 6, 18, 7, 2, 24], авиационную промышленность [31, 23, 35, 29, 34], машиностроение [5, 10, 19, 30, 25] и т.д.

Технологии аддитивного производства воздействуют на все отрасли промышленности и со временем полностью их охватят, по трём основным направлениям:

1. В качестве технологий производства с особыми требованиями к используемым сырьевым материалам. По первому направлению технологии аддитивного производства преобразуют отрасли промышленности, занимающиеся производством сырьевых материалов для отраслей, занимающихся производством комплектующих. В частности, технологии аддитив- 
ного производства ставят новые требования к качеству сырьевых материалов, поставляемых соответствующими отраслями, перерабатывающими природные ресурсы [3, 15, 4];

2. В качестве технологий производства комплектующих. По второму направлению технологии аддитивного производства преобразуют отрасли промышленности, занимающиеся производством комплектующих. В частности, технологии аддитивного производства революционизируют сам характер производства комплектующих, поскольку, в отличие от традиционных производственных линий, использующих технологии субтрактивного производства, основанные на отсечении лишнего от первоначальной заготовки, они основаны на послойном производстве, и, по мере роста производительности труда, создают невиданные возможности для индивидуализированного производства с учётом потребностей и предпочтений заказчика и/ или потребителя [9, 28, 32, 27, 26];

3. В качестве технологий, позволяющих выдавать индивидуализированные комплектующие с такой высокой производительностью, которую не могут обеспечить традиционные производственные линии. По третьему направлению технологии аддитивного производства преобразуют отрасли промышленности, занимающиеся сборкой готовой продукции из комплектующих. В частности, технологии аддитивного производства всё больше индивидуализируют производство комплектующих, что, с учётом тенденции ко всё большей роботизации гибких производственных систем, в том числе с использованием искусственного интеллекта, сделает сборку готовой продукции в рамках «умной фабрики» практически без участия человека полностью индивидуализированной с учётом потребностей и предпочтений заказчика и/или потребителя [21, 16, 1, 17, 22, 33].

Интересно привести обзор результатов исследования французской компании Sculpteo, которая в течение 2018 года провела опрос более чем 1000 руководителей и технических специалистов по всему миру. В 2018 году доля тех, кто считает 3D-печать конкурентным преимуществом возросла с 90\% до 93\%. В 2018 году по сравнению с 2017 годом компании были более склонны инвестировать в 3D-печать. Если согласно данным, полученным от опрошенных руководителей и технических специалистов компаний, в 2017 году у 53\% компаний не было ни одного 3D-принтера, а у 28\% было два и более 3D-принтеров, то в 2018 году уже у 66\% компаний был собственный 3D-принтер, а у 44\% было два и более 3D-принтеров. При этом в сегменте печати пластмассами у $75 \%$ респондентов имеются 3D-принтеры, работающие с использованием FDM-технологии 3D-печати (3D-печать пластиком), у 29\% имеются 3D-принтеры, работающие с использованием SLA-технологии 3D-печати (3D-печать фотополимерной смолой), у 15\% имеются 3D-принтеры, работающие с использованием SLS-технологии 3D-печати (3D-печать порошковыми полимерами), а у 11\% имеются 3D-принтеры, работающие с использованием PolyJet-технологии 3D-печати (3D-печать фотополимерной смолой). Следует отметить, что среди используемых исследуемыми компаниями 3D-принтеров растёт доля более качественных 3D-принтеров. В частности, если в сравнении с 2017 годом доля FDM-принтеров сократилась с 85\% до 75\%, то доли SLA-принтеров, SLS-принтеров и PolyJet-принтеров повысились, соответственно, с 23\% до 29\%, с $8 \%$ до 15\% и с $10 \%$ до $11 \%$. А в сегменте печати металлами зафиксированы следующие показатели роста использования 3D-принтеров: с 1\% до 16\% для DMLS-принтеров и с 1\% до 4\% для SLM-принтеров. Также интересно отметить, что в сравнении с остальными секторами и отраслями 3D-печать намного быстрее проникает в авиационную промышленность, в которой 64\% респондентов используют 3D-печать для производства, хотя для остальных секторов и отраслей этот показатель составил 43\%. В 2018 году 37\% авиационных компаний потратили на 3D-печать более 100 тысяч долларов. При этом 3D-печать металлом использовали 61\% авиационных компаний, хотя для остальных секторов и отраслей этот показатель составил 36\%. Такая заинтересованность авиационных компаний в 3D-печати, которые используют для печати дорогостоящие материалы, говорит о том, что 3D-печать с учётом роста производительности труда под влиянием использования технологий аддитивного производства может использоваться для дополнительного ускорения роста в высокотехнологичных отраслях промышленности.

Проведём обзор российского и мирового рынка 3D-принтеров. Согласно данным британской аналитической компании Context в 2018 году поставки промышленных 3D-принтеров возросли с 4.6 до 5.8 тыс. штук. Поставки про- 
фессиональных и дизайнерских 3D-принтеров в 2018 году по сравнению с 2017 годом также возросли, соответственно, на 50 и 7 тыс. штук, однако, поставки персональных 3D-принтеров сократились с 400 до 370 тыс. штук. Согласно данным той же компании Context, опубликованным в мае 2019 года, в 2018 году мировой рынок материалов для промышленных и профессиональных 3D-принтеров продемонстрировал рост на 29.9\% по сравнению с 2017 годом, а в 2013-2018 годах по сравнению с предыдущими годами средний рост составил $25.98 \%$. Следует отметить, что на мировом рынке в 2014-2018 годах 80.6\% доходов от продаж материалов, используемых для 3D-печати в промышленных и профессиональных 3D-принтерах, приходилось на полимеры, а доля металлов составляла $13.5 \%$. Однако в 2018 году доля металлов для 3D-принтеров возросла до $17.9 \%$, а доля полимеров упала до 78.8\%. Приведём также данные исследования российской компании Discovery Research Group. В 2016 году объём российского рынка 3D-принтеров по сравнению с 2015 годом увеличился с 10158 шт. до 12463 шт. 32\% рынка 3D-принтеров России занимают принтеры, работающие с использованием FDM-технологии, а ключевой потребляющей отраслью для 3D-печати является отрасль потребительских товаров. Объём производства 3D-принтеров в России в 2016 году составил 8100 шт.

Составим примерную схему революционных преобразований в различных отраслях промышленности от природного сырья до готовой продукции на основе технологий аддитивного производства и других самых современных технологий, готовых к внедрению в производство. В результате складывается следующая система с замкнутым циклом безотходного производства с индивидуализированным производством с учётом потребностей и предпочтений отдельных заказчиков и/или потребителей под влиянием технологий аддитивного производства и роботизации гибких производственных систем:

1. Этап переработки природного сырья в материалы для аддитивного производства;

2. Этап аддитивного производства;
3. Этап сборки готовой продукции с помощью роботизированных гибких производственных систем на «умных фабриках»;

4. Этап вторичной избирательной переработки мусора и лома различного характера с помощью роботизации и биотехнологий;

5. Этап переработки вторичного сырья, полученного после вторичной избирательной переработки мусора и лома различного характера, для получения материалов для аддитивного производства.

Исходя из вышеизложенного перечислим основные направления, в которых необходимо действовать на государственном уровне для ускорения научно-технологического развития России на основе технологий 3D-печати. В частности, необходимо государственное стимулирование:

1. Производства отечественных 3D-принтеров, печатающих с использованием самых передовых технологий аддитивного производства;

2. Экспорта отечественных 3D-принтеров с целью поддержки их отечественного производства в условиях временно ограниченного спроса на внутреннем рынке;

3. Импорта 3D-принтеров, не имеющихся аналогов в России, для стимулирования перевода отраслей промышленности с субтрактивного на аддитивное производство;

4. Развития сборки готовой продукции с использованием комплектующих, напечатанных на 3D-принтерах;

5. Производства высококачественных материалов, пригодных для использования в 3D-принтерах;

6. Подготовки кадров мирового класса со средним специальным и высшим образованием в области технологий аддитивного производства.

Указанные меры должны основываться на прямых и косвенных методах государственного воздействия на заинтересованные хозяйствующие единицы в рамках системы стратегического индикативного государственного планирования социально-экономического развития.

\section{Библиографический список}

1. Автоматизированная система управления процессом изготовления высокоточных изделий с применением интеллектуальных технологий / Игнатьев А.А. и соавт. // Успехи современной науки. 2017. Т.4, № 2. С. 88-92; 
2. Аствацатрян Л.Э., Гажва С.И. Современные аспекты использования 3D-технологий в изготовлении съёмных зубных протезов // Современные проблемы науки и образования. 2017. № 5. URL: http://www.scienceeducation.ru/ru/article/view?id=27071 (дата обращения: 01.08.2019);

3. Глазунов В.С., Черепанова М.В. Применение аддитивных технологий в производстве керамических изделий // Вестник Пермского национального исследовательского политехнического университета. Химическая технология и биотехнология. 2018. № 4. С. 174-187;

4. Задорожний Р.Н., Тихонюк А.Р. Модернизация установки для получения порошковых материалов, пригодных для аддитивных технологий // Инновации в сельском хозяйстве. 2018. № 3(28). С. 308-312;

5. Зленко М.А., Нагайщев М.В., Довбыш В.М. Аддитивные технологии в машиностроении. М.: ГНЦ РФ ФГУП «НАМИ», 2015. 220 c.;

6. Использование 3D-принтеров в хирургии (обзор литературы) / Лазаренко В.А. и соавт. // Курский научно-практический вестник «Человек и его здоровье». 2018. № 4. С. 61-65;

7. Калагова А.В. Применение современных технологий 3D-печати в медицине // Молодой учёный. 2019. № 2. C. 54-56;

8. Корбанов В.Д., Вальтер А.И. Изготовление модельной оснастки в литейном производстве с применением аддитивных технологий // Известия Тульского государственного университета. Технические науки. 2018. № 10. С. 334-338;

9. Краснов А.А., Смоленцев Е.В. Аддитивное и субтрактивное производство // Международный научный журнал «Инновационная наука». 2016. № 12-2/2016. С. 72-75;

10. Мишин И.М. Аддитивные технологии в железнодорожном машиностроении // Устойчивое развитие науки и образования. 2018. № 9. С. 215-218;

11. Новые технологии в индустрии питания - 3D-печать / Гришин А.С. и соавт. // Вестник ЮУрГУ. Серия «Пищевые и биотехнологии». 2016. Т. 4, № 2. С. 36-44;

12. Передовые технологии аддитивного производства металлических изделий / Осколков А.А. и соавт. // Вестник Пермского национального политехнического университета. Машиностроение, материаловедение. 2018. Т. 20, № 3. С. 90-105;

13. Применение 3D-печати в стоматологии для изготовления провизорных ортопедических конструкций / Дьяченко Д.Ю. и соавт. // Электронный научно-образовательный вестник здоровье и образование в ХХІ веке. 2015. Т. 17 (3). С. 5-7;

14. Рашковеи М.B., Никулина А.А. Применение аддитивной технологии в производстве сплавов Ni-Cr-Mo и NiCo-Cr // Вестник горно-металлургической секции Российской академии естественных наук. Отделение металлургии. 2018. № 41. С. 207-213;

15. Сун Кай, Сун Ксиа. Разработка трёхмерных композитных печатных материалов // XXI век. Техносферная безопасность. 2018. Т. 3, № 1(9). С. 26-31;

16. Суханова Н.В. Разработка интеллектуальных автоматизированных систем управления в машиностроении // Наукоёмкие технологии в машиностроении. 2018. № 11(89). С. 42-48;

17. Тагирова К.Ф. Архитектура интеллектуальной автоматизированной системы управления насосной установкой нефтедобычи // Высокопроизводительные вычислительные системы и технологии. 2018. Т. 2 , № 2. С. 124-129;

18. Устранение дефектов нижней челюсти эндопротезами, созданными на технологии аддитивного стереолитографического моделирования / Мирзоев М.Ш. и соавт. // Вестник Авиценны. 2018. Т. 20, № 2-3. С. 170-175;

19. Чемодуров А.Н. Применение аддитивных технологий в производстве изделий машиностроения // Известия ТулГУ. Технические науки. 2016. Вып. 8. Ч. 2. С. 210-217;

20. Черепанова М.В., Сковородников П.В., Хазеев А.А. Применение аддитивных технологий в производстве керамических изделий сложных форм // Научный альманах. 2018. № 10-2 (48). С. 73-76;

21. Чуб О.П. Оптимизация параметров гибких производственных систем // Евразийское научное объединение. 2019. № 4-2(50). С. 131-134;

22. Шилкина С.В., Гусарова А.А. Интеллектуальные информационные технологии в автоматизированных системах управления технологическими процессами // Современная наука и инновации. 2018. № 1(21). С. 34-39;

23. Additive Manufacturing for the Aircraft Industry: A Review / Sarat Singamneni et al. // Journal of Aeronautics \& Aerospace Engineering. 2019. Volume 8, Issue 1 https://www.longdom.org/open-access/additive-manufacturingfor-the-aircraft-industry-a-review.pdf (дата обращения: 01.08.2019); 
24. Current Biomedical Applications of 3D Printing and Additive Manufacturing / Pouyan Ahangar et al. // Applied Sciences. 2019. Volume 9, Issue 8. URL: https:/www.mdpi.com/2076-3417/9/8/1713/pdf (дата обращения: 01.08.2019);

25. Daniel Beiderbeck, Dominik Deradjat, Tim Minshall. The Impact of Additive Manufacturing Technologies on Industrial Spare Parts Strategies. Cambridge: University of Cambridge, 2018. 57 p. URL: https://pdfs.semanticscholar.org/fde 3/38bf35690594dc9a4f2822853bab87fb45dc.pdf (дата обращения: 01.08.2019);

26. Design and Characterization of Electrically Conductive Structures Additively Manufactured by Material Extrusion / Hagen Watschke et al. // Applied Sciences. 2019. Volume 9, Issue 4. URL: https://www.mdpi.com/20763417/9/4/779/pdf (дата обращения: 01.08.2019);

27. Effect of Process Parameters on the Generated Surface Roughness of Down-Facing Surfaces in Selective Laser Melting / Amal Charles et al. // Applied Sciences. 2019. Volume 9, Issue 6. URL: https://www.mdpi.com/20763417/9/6/1256/pdf (дата обращения: 01.08.2019);

28. Improving Surface Roughness of Additively Manufactured Parts Using a Photopolymerization Model and MultiObjective Particle Swarm Optimization / Namjung Kim et al. // Applied Sciences. 2019. Volume 9, Issue 1. URL: https://www.mdpi.com/2076-3417/9/1/151/pdf (дата обращения: 01.08.2019);

29. Manda V.R., Kampurath V., Msrk C. 3D Printing and its Effect on Outsourcing: A Study of the Indian Aircraft Industry // Journal Aerospace Technology and Management. 2018. Volume 10. URL: http://www.scielo.br/pdf/ jatm/v10/2175-9146-jatm-10-e0718.pdf (дата обращения: 01.08.2019);

30. MultiFab: A Machine Vision Assisted Platform for Multi-material 3D Printing / Pitchaya Sitthi-Amorn et al. URL: https://core.ac.uk/download/pdf/78067368.pdf (дата обращения: 01.08.2019);

31. Prakash Panneerselvam. Additive Manufacturing in Aerospace and Defense Sector: Strategy of India // Journal of Defense Studies. 2018. Volume 12, № 1.pp. 39-60;

32. Rapid Prototyping of Efficient Electromagnetic Interference Shielding Polymer Composites via Fused Deposition Modeling / Luiz Gustavo Ecco et al.// Applied Sciences. 2019. Volume 9, Issue 1. URL: https://www.mdpi.com/20763417/9/1/37/pdf (дата обращения: 01.08.2019);

33. Real-time Scheduling of Flexible Manufacturing Systems Using Support Vector Machines and Case-Based Reasoning / Paolo Priore et al. // Journal of Economics, Business and Management. 2015. Volume 3, № 1. pp. 5459 ;

34. The Current Landscape for Additive Manufacturing Research. London: Imperial College, 2016. 83 p. URL: https:// core.ac.uk/download/pdf/77018324.pdf (дата обращения: 01.08.2019);

35. Thinking ahead the Future of Additive Manufacturing - Exploring the Research Landscape. Paderborn: Direct Manufacturing Research Center, 2013. 137 p. URL: https://dmrc.uni-paderborn.de/fileadmin/dmrc/06_ Downloads/01_Studies/DMRC_Study_Strategy.pdf (дата обращения: 01.08.2019). 